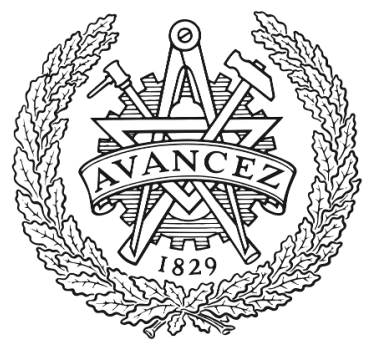

CHALMERS

UNIVERSITY OF TECHNOLOGY

\title{
High Thermoelectric Power Factor of Poly(3-hexylthiophene) through In-Plane Alignment and Doping with a Molybdenum Dithiolene Complex
}

Downloaded from: https://research.chalmers.se, 2023-04-26 10:20 UTC

Citation for the original published paper (version of record):

Untilova, V., Hynynen, J., Hofmann, A. et al (2020). High Thermoelectric Power Factor of

Poly(3-hexylthiophene) through In-Plane Alignment and

Doping with a Molybdenum Dithiolene Complex. Macromolecules, 53(15): 6314-6321.

http://dx.doi.org/10.1021/acs.macromol.0c01223

N.B. When citing this work, cite the original published paper. 


\section{High Thermoelectric Power Factor of Poly(3-hexylthiophene) through In-Plane Alignment and Doping with a Molybdenum Dithiolene Complex}

Viktoriia Untilova, Jonna Hynynen, Anna I. Hofmann, Dorothea Scheunemann, Yadong Zhang, Stephen Barlow, Martijn Kemerink, Seth R. Marder, Laure Biniek, Christian Müller,* and Martin Brinkmann*

Cite This: Macromolecules 2020, 53, 6314-6321

Read Online

\section{ACCESS | Lلll Metrics \& More | 回 Article Recommendations | S1 Supporting Information}

ABSTRACT: We report a record thermoelectric power factor of up to $160 \mu \mathrm{W} \mathrm{m} \mathrm{m}^{-1} \mathrm{~K}^{-2}$ for the conjugated polymer poly(3-hexylthiophene) (P3HT). This result is achieved through the combination of high-temperature rubbing of thin films together with the use of a large molybdenum dithiolene p-dopant with a high electron affinity. Comparison of the UV-visNIR spectra of the chemically doped samples to electrochemically oxidized material reveals an oxidation level of $10 \%$, i.e., one polaron for every 10 repeat units. The high power factor arises due to an increase in the charge-carrier mobility and hence electrical conductivity along the rubbing direction. We conclude that P3HT, with its facile synthesis and outstanding processability, should not be ruled out as a potential thermoelectric material.

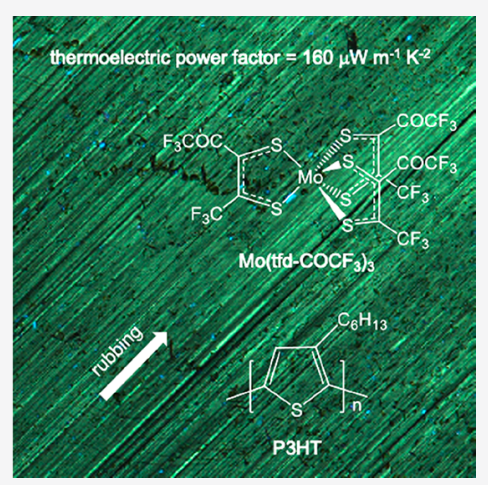

\section{INTRODUCTION}

Conjugated polymers currently receive considerable attention as thermoelectric materials because they are composed of abundant elements and offer ease of processing, low weight, and mechanical robustness. ${ }^{1-3}$ The thermoelectric efficacy of a material can be described by either the dimensionless figure of merit $Z T=\alpha^{2} \sigma T / \kappa$ or the power factor $\alpha^{2} \sigma$, where $\alpha$ is the Seebeck coefficient, $\sigma$ and $\kappa$ are the electrical and thermal conductivity, and $T$ is the absolute temperature. Power factors reported for unoriented conjugated polymers now reach values of $10^{2} \mu \mathrm{W} \mathrm{m} \mathrm{m}^{-1} \mathrm{~K}^{-24-8}$ and in the case of aligned materials more than $10^{3} \mu \mathrm{W} \mathrm{m}{ }^{-1} \mathrm{~K}^{-2}$. 9,10 The majority of studies focus on polythiophenes because they are widely available and can be synthesized with a wide range of molecular weights, sidechain lengths, and regioregularities. As a result, polythiophenes are ideal for elucidating fundamental structure-property relationships that underpin the thermoelectric performance of conjugated polymers. The archetypal semicrystalline conjugated polymer is regioregular poly(3-hexylthiophene) (P3HT), which has been employed in a considerable number of studies related to organic thermoelectrics. Regardless, the highest thermoelectric power factor reported for $\mathrm{P} 3 \mathrm{HT}$ has remained well below $10^{2} \mu \mathrm{W} \mathrm{m}{ }^{-1} \mathrm{~K}^{-2}$ (see Table 1 ), as a result of which many researchers question the relevance of structure-property relationships established with this material.

The power factor of a wide range of organic materials approximately scales according to the empirical power law
Table 1. Selected Literature Values for the Thermoelectric Properties of P3HT at Room Temperature

$\begin{array}{lccccc}\text { dopant } & \text { alignment }^{a} & \begin{array}{c}\sigma \\ \left(\mathrm{S} \mathrm{cm}^{-1}\right)\end{array} & \begin{array}{c}\alpha \\ \left(\mu \mathrm{V} \mathrm{K}^{-1}\right)\end{array} & \begin{array}{c}\alpha^{2} \sigma \\ \left(\mu \mathrm{W} \mathrm{m}^{-1} \mathrm{~K}^{-2}\right)\end{array} & \text { ref } \\ \mathrm{Fe}(\mathrm{TFSI})_{3} & \text { no } & 87 & 48 & 20 & 22 \\ \mathrm{Fe}(\mathrm{TFSI})_{3} & \text { yes } & 251 & 39 & 38 & 19 \\ \mathrm{~F}_{4} \mathrm{TCNQ} & \text { no } & 12.7 & 46 & 2.7 & 12 \\ \mathrm{~F}_{4} \mathrm{TCNQ} & \text { no } & 48 & 85 & 27 & 23 \\ \mathrm{~F}_{4} \mathrm{TCNQ} & \text { yes } & 22 & 60 & 8.5 & 21 \\ \mathrm{~F}_{4} \mathrm{TCNQ} & \text { yes } & 160 & 59 & 56 & 24 \\ \mathrm{Mo}\left(\mathrm{tfd}-_{\mathrm{COCF}}\right)_{3} & \text { yes } & 12.7 & 112 & 16 & 20 \\ \mathrm{Mo}_{3}(\mathrm{tfd})_{3}+ & \text { no } & 68.5 & 8.1 & 4.7 & 17 \\ \mathrm{FeCl}_{3} & & & & & \\ \mathrm{FeCl}_{3} & \text { no } & 42 & 105 & 46 & 6 \\ \mathrm{FeCl} & \text { yes } & 570 & 5.4 & 21 & 9 \\ \mathrm{FTS} & \text { no } & 27.7 & 60 & 10 & 11\end{array}$

${ }^{a}$ For oriented samples highest reported values measured along the direction of alignment are given.

Received: May 25, 2020

Revised: June 22, 2020

Published: July 23, 2020 
$\alpha^{2} \sigma \propto \sqrt{\sigma} .^{11-13}$ Hence, the majority of strategies for increasing the power factor concentrate on improving the electrical conductivity, which is given by

$$
\sigma=N_{v} \mu e
$$

where $N_{v}$ and $\mu$ are the density and mobility of charge carriers and $e$ is the elementary charge.

Charges are created through molecular doping; i.e., dopant molecules are added to the semiconductor, which in the case of p-doping take up an electron, leaving a hole behind. To reach a high conductivity, it is paramount that the fraction of mobile charges created per dopant molecule is as high as possible. However, hole-anion pairs generated upon doping remain Coulombically bound to each other, meaning that most charges are unable to contribute to transport. ${ }^{14,15}$ For instance, Pingel and Neher concluded that only 5\% of charges contribute to transport in P3HT doped with the small molecular dopant 2,3,5,6-tetrafluoro-7,7,8,8-tetracyanoquinodimethane $\left(\mathrm{F}_{4} \mathrm{TCNQ}\right) .{ }^{14}$ Several studies have recently shown that the size of the dopant molecule has a pronounced impact on the electrical conductivity of p-doped $\mathrm{P} 3 \mathrm{HT}$. ${ }^{16,17}$ Liang et al. found that the use of large molybdenum dithiolene complexes, which have a diameter of 11-14 $\AA$, promotes delocalization of the polaron. ${ }^{17}$ Aubry et al. were able to effectively shield the hole polaron from its anion through the use of a large dodecaborane-based dopant with a diameter of $20 \AA$, which boosts the fraction of mobile charge carriers. ${ }^{16}$

In addition to ensuring a high number of mobile charges, it is important that the nanostructure of the polymer enables a high charge-carrier mobility. For molecularly doped P3HT the electrical conductivity strongly depends on the crystallinity of the polymer. ${ }^{12,18}$ Furthermore, uniaxial alignment has been widely explored as a tool to enhance the electrical conductivity and power factor in one direction. Qu et al. used directional epitaxial crystallization of P3HT with help of 1,3,5-trichlorobenzene, followed by doping with $\mathrm{Fe}(\mathrm{TFSI})_{3}$ to reach a power factor of $38 \mu \mathrm{W} \mathrm{m}{ }^{-1} \mathrm{~K}^{-2}$. ${ }^{19}$ In addition, some of us have used tensile drawing of bulk samples ${ }^{20}$ or high-temperature rubbing of thin films ${ }^{9,21}$ to orient P3HT, achieving a power factor of 16 , 21 , and $56 \mu \mathrm{W} \mathrm{m}^{-1} \mathrm{~K}^{-2}$ upon subsequent doping with Mo(tfd$\left.\mathrm{COCF}_{3}\right)_{3}, \mathrm{FeCl}_{3}$, and $\mathrm{F}_{4} \mathrm{TCNQ}$, respectively (see Table 1).

Here, we combine the aforementioned strategies with the aim of increasing the thermoelectric power factor that can be achieved with P3HT. To increase the order of the polymer, we chose to employ high-temperature rubbing, a technique that allows the preparation of highly aligned polymer films with an effective thickness of a few tens of nanometers. As the dopant we selected the molybdenum dithiolene complex Mo(tfd$\left.\mathrm{COCF}_{3}\right)_{3}$ (see Figure 1 for the chemical structure), which due to a high electron affinity of $\mathrm{EA} \sim 5.6 \mathrm{eV}^{25,26}$ offers a large driving force for the oxidation of $\mathrm{P} 3 \mathrm{HT}$.

\section{RESULTS AND DISCUSSION}

In a first set of experiments we studied doping of isotropic P3HT films. Sequential doping was performed by drop-casting solutions of $\mathrm{Mo}\left(\mathrm{tfd}-\mathrm{COCF}_{3}\right)_{3}$ in 1:1 acetonitrile:chloroform (AcN: $\mathrm{CHCl}_{3}$ ) onto doctor-bladed P3HT films. We used an AcN: $\mathrm{CHCl}_{3}$ solvent mixture because it resulted in a higher degree of doping than $\mathrm{AcN}$ solutions $\left(\mathrm{CHCl}_{3}\right.$ would dissolve $\mathrm{P} 3 \mathrm{HT}$ ). The dopant solution was allowed to remain on top of the film for $3 \mathrm{~min}$, followed by spinning off excess solution (see the Experimental Setion for details). We recorded UV-vis-
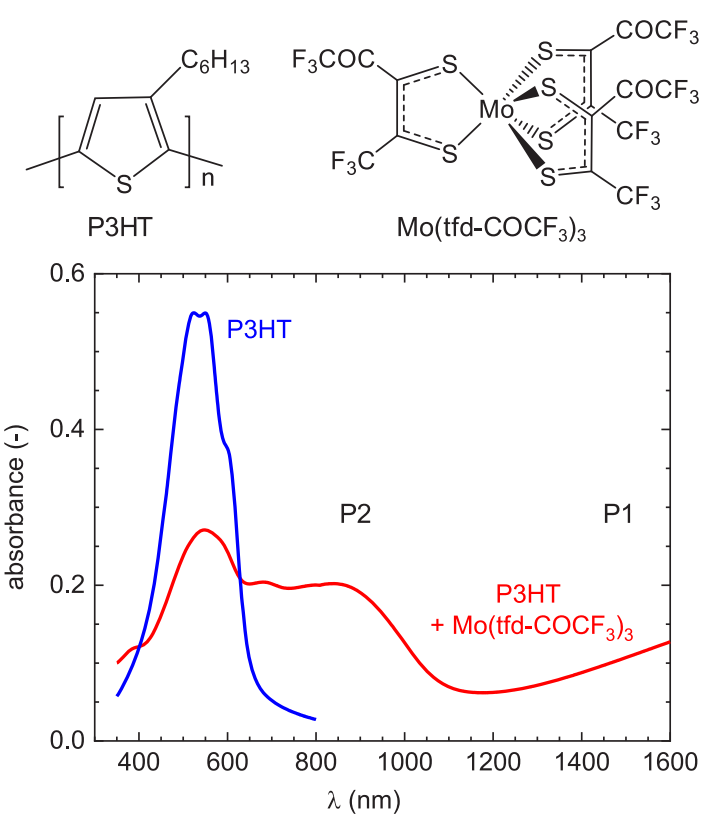

Figure 1. Chemical structure of $\mathrm{P} 3 \mathrm{HT}$ and $\mathrm{Mo}\left(\mathrm{tfd}-\mathrm{COCF}_{3}\right)_{3}$. UVvis-NIR absorbance spectrum of a P3HT film before (blue) and after (red) sequential doping with $\mathrm{Mo}\left(\mathrm{tfd}-\mathrm{COCF}_{3}\right)_{3}\left(c_{\mathrm{Mo}} \sim 1 \mathrm{~g} \mathrm{~L}^{-1}\right)$.

NIR spectra of films doped with solutions containing 0.1, 1, and $7.5 \mathrm{~g} \mathrm{~L} \mathrm{~L}^{-1}$ of the dopant. Doping gives rise to two pronounced absorption bands- $\mathrm{P} 1$ located in the infrared part of the spectrum and $\mathrm{P} 2$ centered at $\lambda_{\mathrm{P} 2} \sim 850 \mathrm{~nm}$ - while the absorption by the neat polymer is diminished in the doped samples (Figure 1 and Figure S1).

We were interested in estimating the number of generated charges, which (assuming that only polarons and no bipolarons are present) can be probed by examining the absolute absorbance of the polaronic peaks. Furthermore, neither neutral $\mathrm{Mo}\left(\mathrm{tfd}-\mathrm{COCF}_{3}\right)_{3}$ nor its anion absorbs at $800 \mathrm{~nm}^{27}$ A combination of spectroelectrochemistry and chronoamperometry allowed us to determine the molar attenuation coefficient $\varepsilon_{\mathrm{P} 2}$ of the first sub-bandgap polaron peak P2. Our electrochemical setup consisted of a spin-coated P3HT film on the indium tin oxide (ITO) working electrode, a platinum wire counter electrode, and a silver wire as pseudo reference electrode, immersed in an electrolyte solution of $0.1 \mathrm{M}$ tetrabutylammonium hexafluorophosphate $\left(\mathrm{TBAPF}_{6}\right)$ in $\mathrm{AcN}$ (see the Experimental Section for details). A cyclic voltammogram of $\mathrm{P} 3 \mathrm{HT}$ indicates an oxidation onset of $E_{\mathrm{ox}} \sim 0.55 \mathrm{~V}$ in our electrochemical setup (Figure 2a; note that the onset of P3HT vs ferrocene/ferrocenium is located at $0 \mathrm{~V}){ }^{28}$ We performed a series of oxidation reactions at constant potentials between 0.55 and $0.75 \mathrm{~V}$ and recorded the transient current $I(t)$ (Figure 2b), which we integrated over time $t$ to obtain the total number of charges $Q$ :

$$
Q=\int_{t=0}^{\infty} I(t) \mathrm{d} t
$$

Normalization by the sample volume in contact with the electrolyte yielded the charge density $Q_{v}$. At the end of each oxidation step we recorded a UV-vis-NIR spectrum and plotted the difference in absorbance $\Delta A$ between doped and undoped P3HT at $800 \mathrm{~nm}$, normalized by the film thickness $d$ $=48 \mathrm{~nm}$ (Figure 2c). A plot of $\Delta A / d$ vs $Q_{y}$ shows a linear trend (Figure 2d), which indicates that only one absorbing 
a

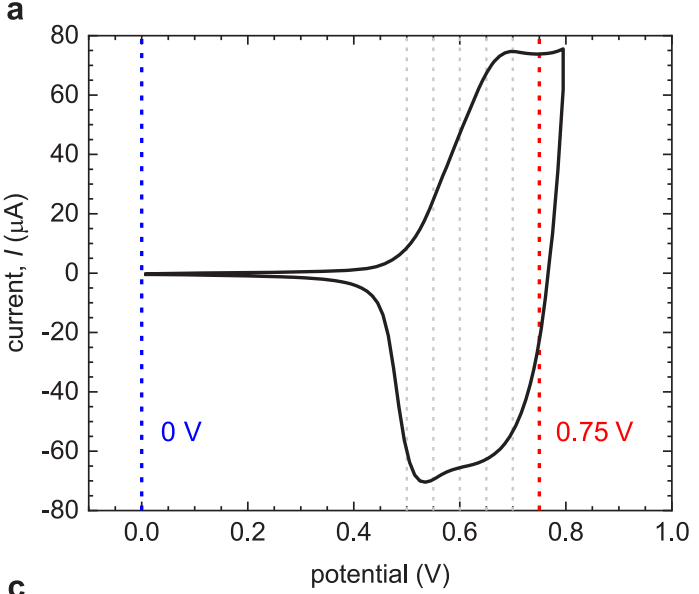

C
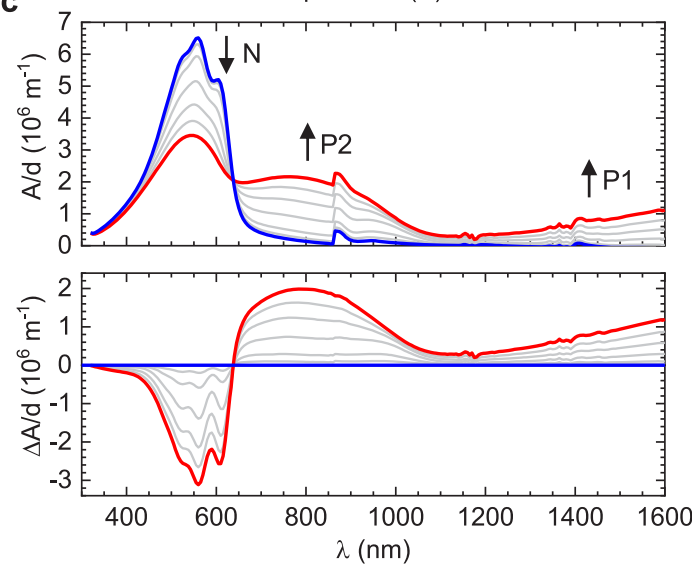

b

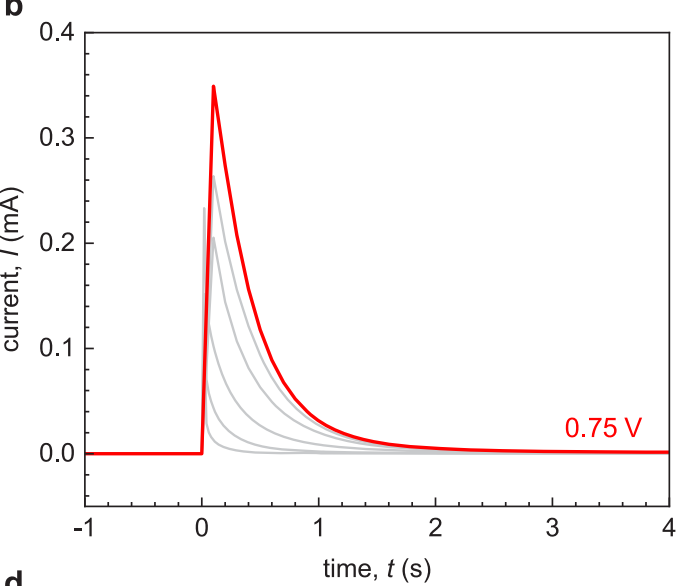

d

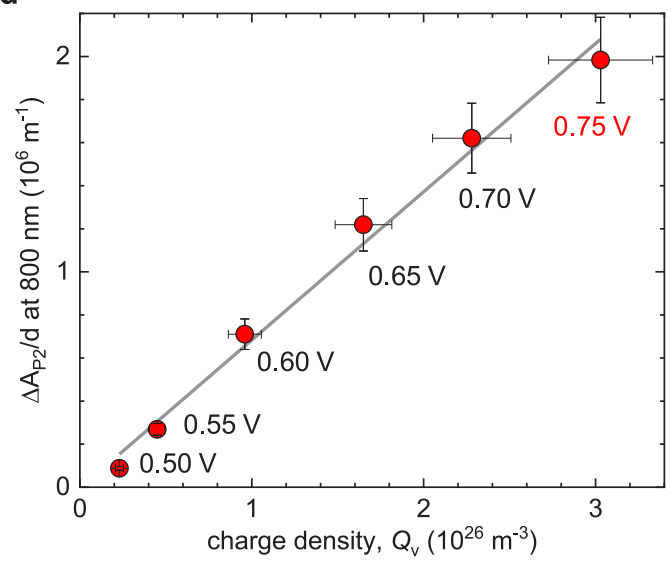

Figure 2. (a) Cyclic voltammogram of $\mathrm{P} 3 \mathrm{HT}$ (P3HT has an oxidation onset around $0 \mathrm{~V}$ vs ferrocene/ferrocenium according to ref 28). (b) Charging current from chronoamperometry. (c) UV-vis-NIR absorbance spectra from spectroelectrochemistry measurements recorded at different electrochemical potentials between $0 \mathrm{~V}$ (blue) and $0.75 \mathrm{~V}$ (red); thickness normalized absorbance $A / d$ (top) and difference in normalized absorbance $\Delta A / d$ between spectra of $\mathrm{P} 3 \mathrm{HT}$ oxidized at different potentials and undoped P3HT at $0 \mathrm{~V}$. (d) Differential absorbance $\Delta A_{\mathrm{P} 2} / d$ at 800 $\mathrm{nm}$ vs charge density $Q_{v}$ from integration of the charging currents; the slope of the linear fit (gray) is the molar attenuation coefficient $\varepsilon_{\mathrm{P} 2}$.

Table 2. Electrical Conductivity $\sigma$, Seebeck Coefficient $\alpha$ (Error $\pm 2 \mu \mathrm{V} \mathrm{K}^{-1}$ ), Power Factor $\alpha^{2} \sigma$, Density and Mobility of Charges $N_{v}$ and $\mu$, and Oxidation Level for Doctor-Bladed Films with a Thickness $d$ Sequentially Doped with an AcN: $\mathrm{CHCl}_{3}$ Solution Containing a Concentration of $c_{\mathrm{Mo}}$ of $\mathrm{Mo}\left(\mathrm{tfd}-\mathrm{COCF}_{3}\right)_{3}{ }^{a}$

$\begin{array}{cccccccc}c_{\mathrm{Mo}}\left(\mathrm{g} \mathrm{L}^{-1}\right) & d(\mathrm{~nm}) & N_{v}\left(10^{26} \mathrm{~m}^{-3}\right) & \text { ox. level }(\mathrm{wt} \%) & \sigma\left(\mathrm{S} \mathrm{cm}^{-1}\right) & \left.\alpha(\mu \mathrm{V} \mathrm{K})^{-1}\right) & \alpha^{2} \sigma\left(\mu \mathrm{W} \mathrm{m} \mathrm{m}^{-1} \mathrm{~K}^{-2}\right) & \mu\left(\mathrm{cm}^{2} \mathrm{~V}^{-1} \mathrm{~s}^{-1}\right) \\ 0.1 & 55 \pm 6 & 0.9 \pm 0.1 & 2 & 1.1 \pm 0.1 & 139 & 2.0 \pm 0.3 & 0.07 \pm 0.01 \\ 1 & 57 \pm 6 & 4.4 \pm 0.5 & 11 & 260 \pm 26 & 44 & 50 \pm 10 & 3.3 \pm 0.5 \\ 7.5 & 51 \pm 5 & 5.0 \pm 0.6 & 13 & 285 \pm 29 & 35 & 35 \pm 8 & 3.2 \pm 0.5\end{array}$

${ }^{a} \sigma$ and $\alpha$ were measured immediately after doping but remained relatively stable during storage in a glovebox for 1 week (Figure S2).

species, i.e., polarons, are present up to a charge density of at least $Q_{v}=3 \times 10^{26} \mathrm{~m}^{-3}$. In agreement, Enengl et al. have shown that a significant amount of bipolarons only starts to form in $\mathrm{P} 3 \mathrm{HT}$ at potentials larger than $0.5 \mathrm{~V}$ above the oxidation onset. ${ }^{29}$ The slope of $\Delta A / d$ vs $Q_{y}$ yields $\varepsilon_{\mathrm{P} 2} \sim(4.1 \pm$ $0.2) \times 10^{3} \mathrm{~m}^{2} \mathrm{~mol}^{-1}$ at $800 \mathrm{~nm}\left(\varepsilon_{\mathrm{P} 2} \sim 41000 \mathrm{M}^{-1} \mathrm{~cm}^{-1}\right)$. We would like to point out that cyclic voltammograms of P3HT can display several anodic waves that correspond to oxidation of ordered and disordered material. ${ }^{28}$ Our analysis is limited to the first anodic wave where ordered P3HT is oxidized, and hence the here reported value for $\varepsilon_{\mathrm{P} 2}$ corresponds to polarons in crystalline domains.

The P2 polaron peak of electrochemically oxidized P3HT is centered at $\lambda_{\mathrm{P} 2} \sim 800 \mathrm{~nm}$, i.e., at a lower wavelength than chemically doped P3HT (cf. Figure 1). We explain this shift in $\lambda_{\mathrm{P} 2}$ with the difference in anion size. During electrochemical oxidation $\mathrm{PF}_{6}^{-}$counterions, which have a thermochemical radius of $r=2.4 \AA \AA^{30}$ enter the polymer from the electrolyte. Chemical doping instead produces $\mathrm{Mo}\left(\mathrm{tfd}-\mathrm{COCF}_{3}\right)_{3}{ }^{-}$counterions, which have a much larger radius of $r \sim 7.5 \AA$ (based on an estimate of the smallest sphere that could encompass the molecule/ion), ${ }^{27}$ and hence results in a larger average polaron-anion distance. ${ }^{31}$ Because the $\mathrm{P} 2$ polaron absorbance is broad, we deem the difference in peak position to be minor. Hence, we used $\varepsilon_{\mathrm{P} 2}$ obtained from our electrochemistry experiments to estimate the charge-carrier density $N_{v}$ of chemically doped P3HT according to the Beer-Lambert law:

$$
\Delta A_{\mathrm{P} 2}=\varepsilon_{\mathrm{P} 2} d N_{v}
$$

where $\Delta A_{\mathrm{P} 2}$ is the difference in absorbance at $800 \mathrm{~nm}$ between doped and undoped P3HT (Table 2). Mo(tfd-COCF $)_{3}$ can dope both ordered and disordered P3HT because of its high 

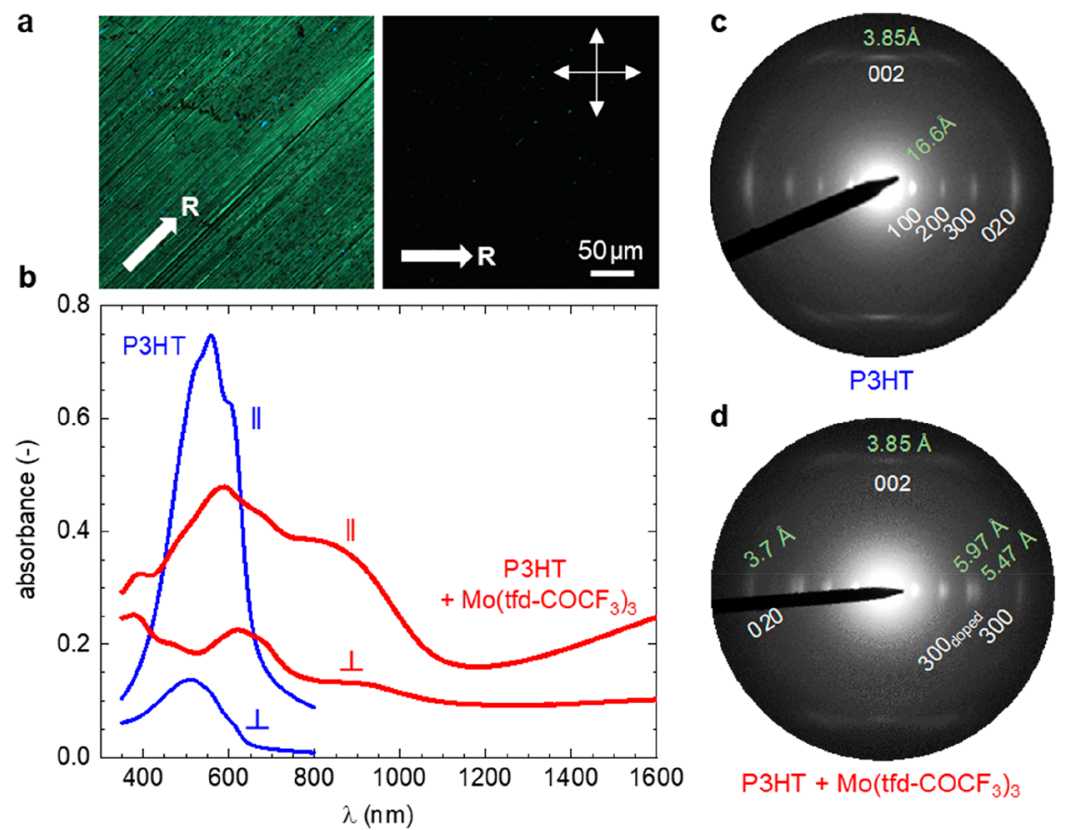

Figure 3. (a) Polarized optical microscopy images of rubbed P3HT films sequentially doped with $c_{\mathrm{Mo}} \sim 1 \mathrm{~g} \mathrm{~L}^{-1}$; crossed double arrows indicate the orientation of polarizer and analyzer; white arrow indicates the rubbing direction $R$. (b) Polarized UV-vis-NIR absorbance spectra of rubbed P3HT and the same P3HT film doped with $c_{\mathrm{Mo}} \sim 1 \mathrm{~g} \mathrm{~L}^{-1} \mathrm{Mo}\left(\mathrm{tfd}_{-} \mathrm{COCF}_{3}\right)_{3}$ measured parallel $(\mathrm{II})$ and perpendicular $(\perp)$ to the rubbing direction $R$. (c, d) Electron diffraction patterns of neat rubbed P3HT and rubbed P3HT doped with $\mathrm{Mo}\left(\mathrm{tfd}-\mathrm{COCF}_{3}\right)_{3}$.

electron affinity of $5.6 \mathrm{eV}$. The here reported value for $\varepsilon_{\mathrm{P} 2}$ was measured by oxidizing ordered P3HT (cf. Figure 2) and may differ in the case of disordered material, which would introduce an error in the here presented analysis of the charge-carrier density. In a recent study we used the same approach to estimate the charge-carrier density of a chemically doped diketopyrrolopyrrole (DPP) based copolymer and could confirm the value obtained for $N_{v}$ with electron paramagnetic resonance (EPR) spectroscopy. ${ }^{32}$ For samples sequentially doped with $c_{\mathrm{Mo}} \sim 1 \mathrm{~g} \mathrm{~L}^{-1} \mathrm{Mo}\left(\mathrm{tfd}-\mathrm{COCF}_{3}\right)_{3}$ in $\mathrm{AcN}: \mathrm{CHCl}_{3}$ we extract a value of $N_{v} \sim(4.4 \pm 0.5) \times 10^{26} \mathrm{~m}^{-3}$. P3HT has a density of about $1.1 \mathrm{~g} \mathrm{~cm}^{-333}$ and hence contains $4 \times 10^{27}$ thiophene rings per $\mathrm{m}^{3}$, which implies an oxidation level of $11 \%$, i.e., one polaron for every ten thiophene repeat units. The same samples display an electrical conductivity of $\sigma \sim(260 \pm$ $26 \mathrm{~S}) \mathrm{cm}^{-1}$, which according to eq 1 translates to a chargecarrier mobility of $\mu \sim(3.3 \pm 0.5) \mathrm{cm}^{2} \mathrm{~V}^{-1} \mathrm{~s}^{-1}$ (Table 2). Note that this value is only slightly higher than the $1 \mathrm{~cm}^{2} \mathrm{~V}^{-1}$ $\mathrm{s}^{-1}$ reported for P3HT doped with $\mathrm{F}_{4}$ TCNQ. ${ }^{34}$ Furthermore, we measured a high Seebeck coefficient of $\alpha \sim 44 \mu \mathrm{V} \mathrm{K}^{-1}$, yielding a thermoelectric power factor of $\alpha^{2} \sigma \sim(50 \pm 10) \mu \mathrm{W}$ $\mathrm{m}^{-1} \mathrm{~K}^{-2}$, which is comparable to the highest values reported for isotropic P3HT (cf. Table 1).

In a further set of experiments, we doped a series of thin-film samples that featured a high degree of in-plane alignment. Oriented samples were prepared by high-temperature rubbing at $186{ }^{\circ} \mathrm{C}$ (see the Experimental Section and refs 21, 35, and 36 for details). We characterized the degree of alignment with polarized optical microscopy (Figure 3a) and polarized UVvis-NIR spectroscopy (Figure $3 \mathrm{~b}$ and Figure S3). The absorption of $\mathrm{P} 3 \mathrm{HT}$ is considerably stronger when measured parallel to the rubbing direction, with a maximum dichroic ratio of $A_{\|} / A_{\perp} \sim 11.5$ at $633 \mathrm{~nm}$, measured for rubbed P3HT (Figure S4), which confirms uniaxial alignment of the conjugated backbone. This is also supported by electron diffraction, which shows that the 002 reflection related to the monomer repeat periodicity $\left(q_{002} \sim 1.63 \AA^{-1}\right)$ is located along the meridian, i.e., along the rubbing direction $R$ (Figure $3 \mathrm{c}$ ). Instead, both the $h 00$ reflections $\left(h=1-3 ; q_{100} \sim 0.379 \AA^{-1}\right)$ associated with lamellar stacking of P3HT and the 020 reflection $\left(q_{020} \sim 1.67 \AA^{-1}\right)$ from $\pi$-stacking are oriented along the equator (Figure 3c). The simultaneous presence of both $h 00$ and 020 reflections is characteristic for a mixture of faceon and edge-on crystalline domains within the polymer films.

Doping of rubbed films was again done by sequential doping with $\mathrm{Mo}\left(\mathrm{tfd}-\mathrm{COCF}_{3}\right)_{3}$ dissolved in $\mathrm{AcN}: \mathrm{CHCl}_{3}$. We note that the positions of the $h 00$ reflections $(h=1-3)$ split upon doping with $\mathrm{Mo}\left(\mathrm{tfd}-\mathrm{COCF}_{3}\right)_{3}$ (Figure $\left.3 \mathrm{~d}\right)$. For instance, we observe two 300 reflections: one close to the original position at $q_{300} \sim 1.15 \AA^{-1}$ and one at $q_{300} \sim 1.05 \AA^{-1}$. The 020 peak related to $\pi$-stacking does not split but slightly shifts to $q_{020} \sim$ $1.70 \AA^{-1}$, whereas the 002 reflection is unchanged. These observations indicate that the films contain both nondoped and doped P3HT crystallites, with the dopant intercalated in the side chain layers as suggested by the expansion of the lattice along the side chain direction.

Interestingly, rinsing of as-doped samples with $\mathrm{AcN}$ reverts the diffraction pattern to that of neat P3HT (Figure S5). Rinsing reduces the oxidation level, indicated by an increase in the neutral polymer absorbance (Figure S6), and leads to a 3fold reduction in electrical conductivity. Analysis of the P2 absorbance band indicates a slight reduction in charge-carrier density to $N_{v} \sim(3.3 \pm 0.4) \times 10^{26} \mathrm{~m}^{-3}$. We argue that the dopant that remains after rinsing is only located in amorphous regions.

Polarized UV-vis-NIR spectra reveal a significant reduction of the neutral polymer absorption independent of the dopant concentration $\left(c_{\mathrm{Mo}} \sim 1,2.5\right.$, and $\left.7.5 \mathrm{~g} \mathrm{~L}^{-1}\right)$, indicating that all samples were strongly doped. The two polaron absorbance peaks in the near and far-IR display considerable anisotropy with the stronger absorbance when measured parallel to the rubbing direction (cf. Figure $3 b$ ). We argue that 
Table 3. Electrical Conductivity $\sigma$, Seebeck Coefficient $\alpha$ (Error $\pm 2 \mu \mathrm{V} \mathrm{K}{ }^{-1}$ ), Power Factor $\alpha^{2} \sigma$, Density and Mobility of Charges $N_{v}$ and $\mu$, and Oxidation Level for Rubbed Films with a Thickness $d$ Sequentially Doped with an $\mathrm{AcN} \mathrm{CHCl}_{3}$ Solution Containing a Concentration of $c_{\mathrm{Mo}}$ of $\mathrm{Mo}\left(\mathrm{tfd}-\mathrm{COCF}_{3}\right)_{3}{ }^{a}$

\begin{tabular}{|c|c|c|c|c|c|c|c|c|c|c|c|}
\hline$\left(\mathrm{g} \mathrm{L}^{c_{\mathrm{Mo}}}\right)$ & $\begin{array}{c}d \\
(\mathrm{~nm})\end{array}$ & $\underset{\left(10^{26} \mathrm{~m}^{-3}\right)}{N_{v}}$ & $\begin{array}{l}\text { ox. level } \\
(\%)\end{array}$ & $\left(\begin{array}{c}\sigma_{\|} \\
(\mathrm{S} \mathrm{cm}\end{array}\right)$ & $\left(\begin{array}{c}\sigma_{\perp} \\
\left(\mathrm{S} \mathrm{cm} \mathrm{cm}^{-1}\right.\end{array}\right)$ & $\underset{\left(\mu \mathrm{V}_{\|} \mathrm{K}^{-1}\right)}{\left.\alpha_{1}\right)}$ & $\begin{array}{c}\alpha_{\perp} \\
\left(\mu \mathrm{V}^{-1}\right)\end{array}$ & $\begin{array}{c}\alpha_{\|}^{2} \sigma_{\|} \\
\left(\mu \mathrm{W} \mathrm{m}^{-1} \mathrm{~K}^{-2}\right)\end{array}$ & $\begin{array}{c}\alpha_{\perp}^{2} \sigma_{\perp} \\
\left(\mu \mathrm{W} \mathrm{m}^{-1} \mathrm{~K}^{-2}\right)\end{array}$ & $\left(\mathrm{cm}^{2} \stackrel{\mu_{\|}}{\mathrm{V}^{-1}} \mathrm{~s}^{-1}\right)$ & $\left(\mathrm{cm}^{2} \stackrel{\mu_{\perp}}{\mathrm{V}^{-1}} \mathrm{~s}^{-1}\right)$ \\
\hline 1 & 44 & $4.0 \pm 0.4$ & 10 & $509 \pm 51$ & $84 \pm 8$ & 56 & 13 & $160 \pm 27$ & $1.0 \pm 0.5$ & $7.1 \pm 1.1$ & $1.2 \pm 0.2$ \\
\hline 2.5 & 58 & $3.6 \pm 0.4$ & 9 & $593 \pm 59$ & $116 \pm 12$ & 47 & 17 & $131 \pm 12$ & $3.0 \pm 0.8$ & $9.3 \pm 1.4$ & $1.8 \pm 0.3$ \\
\hline 7.5 & 53 & $4.4 \pm 0.5$ & 11 & $681 \pm 68$ & $50 \pm 5$ & 43 & 6 & $126 \pm 12$ & $0.2 \pm 0.1$ & $8.7 \pm 1.3$ & $0.6 \pm 0.1$ \\
\hline
\end{tabular}

${ }^{a}$ Subscripts II and $\perp$ refer to in-plane values measured parallel and perpendicular to the rubbing direction; $\sigma$ and $\alpha$ were measured immediately after doping but remained relatively stable during storage in a glovebox for 1 week and even after subsequent exposure to air (Figure S2).

polarons delocalize along the oriented polymer backbone as recently confirmed by Ghosh et al. ${ }^{37}$ We again used the molar attenuation coefficient $\varepsilon_{\mathrm{P} 2}$ to estimate the number of charge carriers. To be able to compare the polarized absorbance of the rubbed samples with the isotropic absorbance of electrochemically oxidized P3HT, we used the average absorbance $\Delta A_{\mathrm{P} 2}=$ $\left(\Delta A_{\|}+\Delta A_{\perp}\right) / 2$ at $800 \mathrm{~nm}$ (cf. Figure $3 \mathrm{~b}$ ). From this value we subtracted $A_{\perp}$ of rubbed and doped films at $1200 \mathrm{~nm}$ to account for the apparent vertical offset of the UV-vis-NIR spectra, which we tentatively assign to light scattering by excess dopant on top of the film (cf. Figure S6). The deduced chargecarrier density of rubbed films is comparable to values extracted for isotropic samples (Table 3). For rubbed P3HT films doped with $c_{\mathrm{Mo}} \sim 1 \mathrm{~g} \mathrm{~L}^{-1} \mathrm{Mo}\left(\mathrm{tfd}-\mathrm{COCF}_{3}\right)_{3}$ we obtain $N_{v}$ $\sim(4.0 \pm 0.4) \times 10^{26} \mathrm{~m}^{-3}$, which corresponds to an oxidation level of $10 \%$.

The electrical conductivity is considerably higher along the rubbing direction, e.g., $\sigma_{\|} \sim(509 \pm 51) \mathrm{S} \mathrm{cm}^{-1}$ vs $\sigma_{\perp} \sim(84 \pm$ 8) $\mathrm{S} \mathrm{cm}^{-1}$ for P3HT doped with $c_{\mathrm{Mo}} \sim 1 \mathrm{~g} \mathrm{~L}^{-1} \mathrm{Mo}(\mathrm{tfd}-$ $\left.\mathrm{COCF}_{3}\right)_{3}$ (Table 3), which gives rise to an anisotropy of $\sigma_{\|} / \sigma_{\perp}$ $\sim 6$ (see Figure S2 for stability of conductivity over time). Together with our estimate for $N_{v}$, we calculate a charge-carrier mobility of $\mu_{\|} \sim(7.1 \pm 0.1) \mathrm{cm}^{2} \mathrm{~V}^{-1} \mathrm{~s}^{-1}$ and $\mu_{\perp} \sim(1.2 \pm 0.2)$ $\mathrm{cm}^{2} \mathrm{~V}^{-1} \mathrm{~s}^{-1}$, which represent average values for all mobile plus bound charges. We note that $\mu_{\|}$is significantly higher than values measured for isotropic samples (cf. Table 2), while $\mu_{\perp}$ is lower.

In agreement with previous studies, ${ }^{9,21,24}$ the Seebeck coefficient also displays a high degree of in-plane anisotropy, e.g., $\alpha_{\|} / \alpha_{\perp} \sim 4$ in the case of P3HT doped with $c_{\text {Mo }} \sim 1 \mathrm{~g} \mathrm{~L}^{-1}$ $\mathrm{Mo}\left(\mathrm{tfd}-\mathrm{COCF}_{3}\right)_{3}$. An absolute Seebeck coefficient of $\alpha_{\|} \sim(56$ $\pm 2) \mu \mathrm{V} \mathrm{K}^{-1}$ gives rise to a maximum power factor of $\alpha_{\|}^{2} \sigma_{\|} \sim$ $(160 \pm 27) \mu \mathrm{W} \mathrm{m}^{-1} \mathrm{~K}^{-2}$ (Table 3), which is the highest value so far reported for P3HT (cf. Table 1). We note that $\alpha_{\|}^{2} \sigma_{\|}$ slightly exceeds the empirical trend $\alpha^{2} \sigma \propto \sqrt{\sigma}$ that is often observed for isotropic samples, ${ }^{11-13}$ while $\alpha_{\perp}{ }^{2} \sigma_{\perp}$ falls short of the predicted value (Figure S7).

The anisotropy of the Seebeck coefficient and conductivity was recently studied by using kinetic Monte Carlo (kMC) simulations to describe thermoelectric measurements on doped poly(2,5-bis(3-dodecyl-2-thienyl)thieno[3,2-b]thiophene) (PBTTT). ${ }^{38}$ In brief, these kMC simulations account for variable-range hopping on a regular lattice. Structural anisotropy is reflected in the model by an increased delocalization in the parallel direction compared to the perpendicular direction; i.e., $\xi_{\|}>\xi_{\perp}$ where $\xi$ is the localization length (cf. ref 38 for details). This model can reproduce the trend of the experimental data in the parallel and perpendicular direction measured for rubbed P3HT doped with $\mathrm{Mo}(\mathrm{tfd}-$ $\left.\mathrm{COCF}_{3}\right)_{3}$, when assuming an anisotropy ratio of $\xi_{\|} / \xi_{\perp}=4$ and an attempt-to-hop frequency of $\nu_{0}=2 \times 10^{13} \mathrm{~s}^{-1}$ (cf. Figure 4).

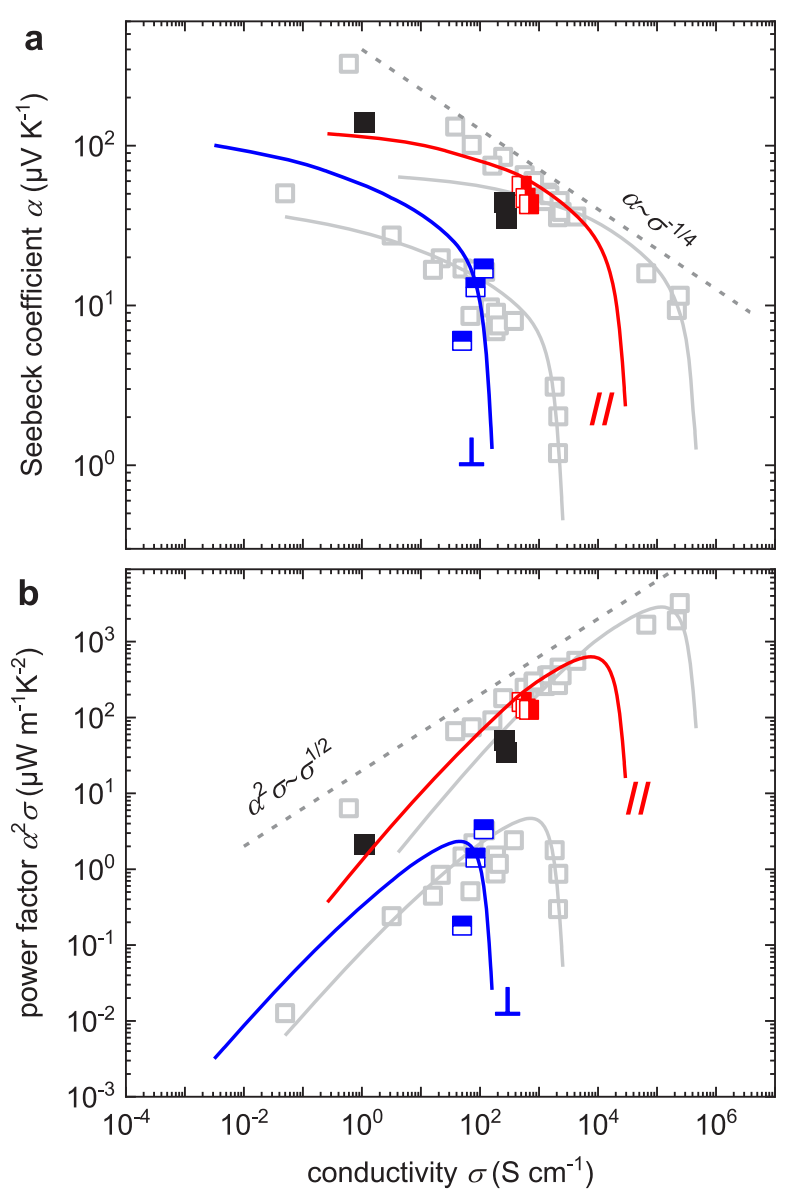

Figure 4. (a) Seebeck coefficient $\alpha$ and (b) power factor $\alpha^{2} \sigma$ vs electrical conductivity $\sigma$ of isotropic P3HT (black squares) and rubbed P3HT measured parallel (red squares and line) and perpendicular to the rubbing direction (blue squares and line); gray data points are literature values extracted from refs 9 and 38 for PBTTT. Full lines correspond to simulations calculated from the $\mathrm{kMC}$ model, with an anisotropy ratio of $\xi_{\|} / \xi_{\perp}=4$, where $\xi_{\|}$and $\xi_{\perp}$ are the localization length in the parallel and perpendicular direction, respectively. The attempt to hop frequency was set to $\nu_{0}=2 \times 10^{13}$ $\mathrm{s}^{-1}$, and the thermopower was rescaled by a factor of 0.1 in both directions. $\|$ and $\perp$ refer to the parallel and perpendicular direction, respectively. The dashed gray line shows the empirical trends $\alpha \propto$ $\sigma^{-0.25}$ and $\alpha^{2} \sigma \propto \sqrt{\sigma}$.

We argue that transport in the highly doped samples studied here is dominated by hopping between discrete sites along the direction of orientation, while interchain transport only plays a minor role. ${ }^{18,38}$ In a system with such a distinct orientation, carriers are forced to hop along the parallel direction and therefore have a limited ability to optimize their path with respect to energy. This results in an upward shift of the 
transport energy $E_{\mathrm{tr}}$ in the parallel direction and as $\alpha \propto\left(E_{\mathrm{F}}-\right.$ $\left.E_{\mathrm{tr}}\right) / T$ with $E_{\mathrm{F}}$ the Fermi energy also in an increase of $\alpha_{\|}$ compared to $\alpha_{\perp}{ }^{38}$

\section{CONCLUSIONS}

We conclude that the combination of a large dopant such as $\mathrm{Mo}\left(\mathrm{tfd}-\mathrm{COCF}_{3}\right)_{3}$ in combination with structural anisotropy, here achieved by high-temperature rubbing, is a powerful means to improve the thermoelectric properties of conjugated polymers. A high conductivity of $\sigma_{\|} \sim(509 \pm 51) \mathrm{S} \mathrm{cm}^{-1}$ is obtained thanks to a high charge-carrier mobility along the rubbing direction. At the same time, the Seebeck coefficient remains high with $\alpha_{\|} \sim(56 \pm 2) \mu \mathrm{V} \mathrm{K}^{-1}$, and as a result we achieve a record thermoelectric power factor of $\alpha_{\|}{ }^{2} \sigma_{\|} \sim(160$ $\pm 27) \mu \mathrm{W} \mathrm{m}{ }^{-1} \mathrm{~K}^{-2}$ for P3HT.

\section{EXPERIMENTAL SECTION}

Materials. P3HT was purchased from Merck $\left(M_{\mathrm{n}}=24 \mathrm{~kg} \mathrm{~mol}^{-1}\right.$, PDI $=1.8$, regioregularity $=95.9 \%)$. Sodium polystyrenesulfonate (NaPSS) was purchased from Sigma-Aldrich. $\mathrm{Mo}\left(\mathrm{tfd}-\mathrm{COCF}_{3}\right)_{3}$ was synthesized as previously described. ${ }^{26}$ Anhydrous acetonitrile (AcN; purity $>99.9 \%)$, chloroform $\left(\mathrm{CHCl}_{3}\right.$; purity $\left.>99.5 \%\right)$, o-dichlorobenzene (oDCB; purity >99\%), and $\mathrm{TBAPF}_{6}$ were purchased from Sigma-Aldrich and used as received.

Orientation and Doping of Thin Films. P3HT films were prepared by doctor-blading a hot solution of $\mathrm{P} 3 \mathrm{HT}$ dissolved in oDCB $\left(10 \mathrm{~g} \mathrm{~L}^{-1}\right)$ at $165^{\circ} \mathrm{C}$ on glass substrates coated with a thin layer of NaPSS (spin-coated from $10 \mathrm{~g} \mathrm{~L}^{-1}$ aqueous solution). The orientation of thin P3HT films by high-temperature rubbing followed the protocol described in refs 21,35 , and 36 and was performed by using a home-built rubbing machine consisting of a translating hot plate at $186^{\circ} \mathrm{C}$, on which the sample is placed, and a rotating cylinder covered with a microfiber cloth. The effective thickness was estimated by comparing the UV-vis absorbance of annealed films $\left(315{ }^{\circ} \mathrm{C}\right.$ for 5 $\min$ ) at $557 \mathrm{~nm}$ with the calibration curve provided in Figure S8. All doping experiments were performed under an inert atmosphere in a glovebox from Jacomex. Dopant solutions were prepared by mixing equal amounts of $\mathrm{AcN}$ and $\mathrm{CHCl}_{3}$, followed by addition of $\mathrm{Mo}(\mathrm{tfd}-$ $\left.\mathrm{COCF}_{3}\right)_{3}$ powder yielding a concentration of $7.5 \mathrm{~g} \mathrm{~L}^{-1}$. Lower concentrations $\left(0.1,1\right.$, and $\left.2.5 \mathrm{~g} \mathrm{~L}^{-1}\right)$ were obtained by dilution of the $7.5 \mathrm{~g} \mathrm{~L}^{-1}$ stock solution with 1:1 AcN: $\mathrm{CHCl}_{3}$. Doping was performed by drop-casting the dopant solution on top of P3HT films, which was left in contact for $3 \mathrm{~min}$ before spinning off the solution. Sequential doping did not alter the film thickness as indicated by atomic force microscopy (AFM) of a spin-coated P3HT film before and after doping (30 vs $31 \mathrm{~nm}$ ) using a Digital Instruments Nanoscope IIIA.

UV-vis-NIR Spectroscopy. UV-vis-NIR absorbance spectra of chemically doped samples were recorded with a Varian Cary 5000 spectrometer. Polarized incident light was used in the case of rubbed thin films. The spectral resolution was $1 \mathrm{~nm}$.

Spectroelectrochemistry. For the spectroelectrochemical measurements thin $\mathrm{P} 3 \mathrm{HT}$ films were cast onto ITO-coated glass (width 6 $\mathrm{mm}$ ) via spin-coating from a solution of $10 \mathrm{~g} \mathrm{~L}^{-1} \mathrm{P} 3 \mathrm{HT}$ in oDCB. The spectroelectrochemical setup consisted of a $1 \mathrm{~cm} \times 1 \mathrm{~cm} \mathrm{UV-vis}$ quartz cuvette with a custom-made Teflon lid, which holds a threeelectrode setup comprising the ITO/polymer sample as a working electrode, a platinum wire counter electrode, and a silver wire as pseudo-reference electrode. All electrochemical measurements were performed in a solution of $0.1 \mathrm{M} \mathrm{TBAPF}_{6}$ in dry and degassed acetonitrile; the potential scale of our setup lies at $0.4-0.5 \mathrm{~V}$ relative to ferrocene/ferrocenium. Cyclic voltammetry was performed at 100 $\mathrm{mV} \mathrm{s}^{-1}$. For chronoamperometry measurements the film was first dedoped upon application of a potential of $0 \mathrm{~V}$ for $60 \mathrm{~s}$, before the respective positive oxidation potential between 0.55 and $0.75 \mathrm{~V}$ was applied for $300 \mathrm{~s}$. UV-vis-NIR absorption spectra were recorded by using a PerkinElmer Lambda 1050 spectrophotometer after $120 \mathrm{~s}$ once the electrochemical current had stabilized. The amount of injected charges was calculated by integrating the electrochemical current over time by using the background current as the baseline. The charge-carrier density was calculated by diving the amount of the injected charge carriers by the film volume in contact with the electrolyte. The film thickness was estimated by comparing the peak absorbance of undoped P3HT at $557 \mathrm{~nm}$ with the calibration curve provided in Figure S8.

Transmission Electron Microscopy (TEM). Samples were prepared by first depositing a thin amorphous carbon layer on top of pieces of oriented polymer films on NaPSS/glass substrates by using an auto 306 Edwards evaporator. Then, oriented areas were identified with an optical microscope (Leica DMR-X) and floated off on distilled water, which dissolved the sacrificial NaPSS layer. The carbon-coated P3HT films were recovered on TEM copper grids. Finally, grids were immediately doped by dropping $10 \mu \mathrm{L}$ of the dopant solution onto the samples, which dried on the sample through evaporation of the solvent. TEM was performed in bright field and diffraction mode by using a CM12 Philips microscope equipped with a MVIII (Soft Imaging System) charge coupled device camera. To avoid dedoping under the electron beam, the exposure was set to a minimum by using the low-dose system.

Thermoelectric Measurements. Samples were fabricated by using the procedure described in refs 8 and 21 . Gold contacts $(40 \mathrm{~nm}$ thick) in a four-point probe geometry $(1 \mathrm{~mm}$ spacing between electrodes, $5 \mathrm{~mm}$ length) were deposited on glass substrates via controlled thermal evaporation through a shadow mask. A first layer of chromium (2.5 nm thick) was deposited prior to the gold to promote adhesion. The geometry of deposited gold electrodes allowed determination of electrical resistivity and thermopower for the same sample both parallel and perpendicular to the rubbing direction. Oriented films of P3HT on NaPSS/glass were floated off with distilled water, recovered with glass substrates on which gold electrodes had been deposited, and finally doped in a glovebox (Jacomex). Thermoelectrical characterization was performed immediately after doping. A Keithley 4200-SCS and a Lab Assistant Semiprobe station in the glovebox under a nitrogen atmosphere were used to determine the sheet resistance $R_{s}$ (using a four-point probe geometry) and thermopower, following the procedure described in refs 8 and 21 . The resistivity $\rho$ was obtained according to $\rho=1.81 R_{s d}$, where $d$ is the film thickness (determination of the geometrical correction factor 1.81 is described in ref 21). Reported conductivity values are the average of two to four samples. The thermopower was measured via the differential temperature method as described in ref 21 by establishing a temperature gradient across the sample either along or perpendicular to the rubbing direction.

\section{ASSOCIATED CONTENT}

\section{SI Supporting Information}

The Supporting Information is available free of charge at https://pubs.acs.org/doi/10.1021/acs.macromol.0c01223.

UV-vis-NIR spectra of neat and doped P3HT films; electrical conductivity vs time; dichroic ratio of rubbed P3HT; electron diffraction patterns of rubbed and doped P3HT before and after rinsing with acetonitrile; plots of Seebeck coefficient and thermoelectric power factor vs electrical conductivity; UV-vis absorbance spectra vs film thickness (PDF)

\section{AUTHOR INFORMATION}

\section{Corresponding Authors}

Christian Müller - Department of Chemistry and Chemical Engineering, Chalmers University of Technology, 41296 Göteborg, Sweden; 이이이.org/0000-0001-7859-7909; Email: christian.muller@chalmers.se

Martin Brinkmann - CNRS, ICS UPR 22, Université de

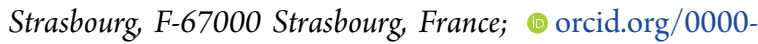


0002-2680-1506; Email: martin.brinkmann@icscnrs.unistra.fr

\section{Authors}

Viktoriia Untilova - CNRS, ICS UPR 22, Universite de Strasbourg, F-67000 Strasbourg, France

Jonna Hynynen - Department of Chemistry and Chemical Engineering, Chalmers University of Technology, 41296 Göteborg, Sweden

Anna I. Hofmann - Department of Chemistry and Chemical Engineering, Chalmers University of Technology, 41296 Göteborg, Sweden; orcid.org/0000-0002-4480-6028

Dorothea Scheunemann - Department of Chemistry and Chemical Engineering, Chalmers University of Technology, 41296 Göteborg, Sweden

Yadong Zhang - School of Chemistry \& Biochemistry and Center for Organic Photonics and Electronics, Georgia Institute of Technology, Atlanta, Georgia 30332-0400, United States

Stephen Barlow - School of Chemistry \& Biochemistry and Center for Organic Photonics and Electronics, Georgia Institute of Technology, Atlanta, Georgia 30332-0400, United States; (i) orcid.org/0000-0001-9059-9974

Martijn Kemerink - Centre for Advanced Materials, Heidelberg University, 69120 Heidelberg, Germany; 이이.org/00000002-7104-7127

Seth R. Marder - School of Chemistry \& Biochemistry and Center for Organic Photonics and Electronics, Georgia Institute of Technology, Atlanta, Georgia 30332-0400, United States; (i) orcid.org/0000-0001-6921-2536

Laure Biniek - CNRS, ICS UPR 22, Université de Strasbourg, F-67000 Strasbourg, France; (1) orcid.org/0000-0002-76433713

Complete contact information is available at: https://pubs.acs.org/10.1021/acs.macromol.0c01223

\section{Notes}

The authors declare no competing financial interest.

\section{ACKNOWLEDGMENTS}

J.H., A.I.H., and C.M. gratefully acknowledge financial support from the Swedish Research Council through Grants 201606146 and 2018-03824, the Knut and Alice Wallenberg Foundation through a Wallenberg Academy Fellowship, and the European Research Council (ERC) under Grant Agreement 637624. D.S. acknowledges funding from the European Union's Horizon 2020 research and innovation program under the Marie Skłodowska-Curie Grant Agreement 799477. S.R.M., S.B., and Y.Z. thank the U.S. National Science Foundation for support of this work through the DMREF program under Award DMR-1729737. V.U. acknowledges financial support from the IRTG Softmatter project. M.B. thanks the Agence Nationale de la Recherche for financial support through project ANR-17-CE05-0012. We thank Christian Blanck and Marc Schmutz for technical support with TEM.

\section{REFERENCES}

(1) Bubnova, O.; Crispin, X. Towards polymer-based organic thermoelectric generators. Energy Environ. Sci. 2012, 5, 9345.

(2) Russ, B.; Glaudell, A.; Urban, J. J.; Chabinyc, M. L.; Segalman, R. A. Organic Thermoelectric Materials for Energy Harvesting and Temperature Control. Nat. Rev. Mater. 2016, 1, 16050.
(3) Kroon, R.; Mengistie, D. A.; Kiefer, D.; Hynynen, J.; Ryan, J. D.; Yu, L.; Müller, C. Thermoelectric Plastics: From Design to Synthesis, Processing and Structure-Property Relationships. Chem. Soc. Rev. 2016, 45, 6147.

(4) Bubnova, O.; Khan, Z. U.; Malti, A.; Braun, S.; Fahlman, M.; Berggren, M.; Crispin, X. Optimization of the thermoelectric figure of merit in the conducting polymer poly(3,4-ethylenedioxythiophene). Nat. Mater. 2011, 10, 429.

(5) Kim, G. H.; Shao, L.; Zhang, K.; Pipe, K. P. Engineered doping of organic semiconductors for enhanced thermoelectric efficiency. Nat. Mater. 2013, 12, 719.

(6) Jung, I. H.; Hong, C. T.; Lee, U.-H.; Kang, Y. H.; Jang, K.-S.; Cho, S. Y. High Thermoelectric Power Factor of a Diketopyrrolopyrrole-Based Low Bandgap Polymer via Finely Tuned Doping Engineering. Sci. Rep. 2017, 7, 44704.

(7) Patel, S. N.; Glaudell, A. M.; Peterson, K. A.; Thomas, E. M.; O'Hara, K. A.; Lim, E.; Chabinyc, M. L. Morphology Controls the Thermoelectric Power Factor of a Doped Semiconducting Polymer. Sci. Adv. 2017, 3.e1700434.

(8) Vijayakumar, V.; Zaborova, E.; Biniek, L.; Zeng, H.; Herrmann, L.; Carvalho, A.; Boyron, O.; Leclerc, N.; Brinkmann, M. Effect of Alkyl Side Chain Length on Doping Kinetics, Thermopower, and Charge Transport Properties in Highly Oriented F4TCNQ-Doped PBTTT Films. ACS Appl. Mater. Interfaces 2019, 11, 4942.

(9) Vijayakumar, V.; Zhong, Y.; Untilova, V.; Bahri, M.; Herrmann, L.; Biniek, L.; Leclerc, N.; Brinkmann, M. Bringing Conducting Polymers to High Order: Toward Conductivities beyond $10^{5} \mathrm{~S} \mathrm{~cm}^{-1}$ and Thermoelectric Power Factors of $2 \mathrm{~mW} \mathrm{~m}^{-1} \mathrm{~K}^{-2}$. Adv. Energy Mater. 2019, 9, 1900266.

(10) Nogami, Y.; Kaneko, H.; Ishiguro, T.; Takahashi, A.; Tsukamoto, J.; Hosoito, N. On the Metallic States in Highly Conducting Iodine-Doped Polyacetylene. Solid State Commun. 1990, 76, 583.

(11) Glaudell, A. M.; Cochran, J. E.; Patel, S. N.; Chabinyc, M. L. Impact of the Doping Method on Conductivity and Thermopower in Semiconducting Polythiophenes. Adv. Energy Mater. 2015, 5, 1401072.

(12) Hynynen, J.; Kiefer, D.; Müller, C. Influence of crystallinity on the thermoelectric power factor of P3HT vapour-doped with F4TCNQ. RSC Adv. 2018, 8, 1593.

(13) Beretta, D.; Neophytou, N.; Hodges, J. M.; Kanatzidis, M. G.; Narducci, D.; Martin-Gonzalez, M.; Beekman, M.; Balke, B.; Cerretti, G.; Tremel, W.; Zevalkink, A.; Hofmann, A. I.; Müller, C.; Dörling, B.; Campoy-Quiles, M.; Caironi, M. Thermoelectrics: From history, a window to the future. Mater. Sci. Eng., R 2019, 138, 100501.

(14) Pingel, P.; Neher, D. Comprehensive picture of p-type doping of P3HT with the molecular acceptor F4TCNQ. Phys. Rev. B: Condens. Matter Mater. Phys. 2013, 87, 115209.

(15) Zuo, G.; Abdalla, H.; Kemerink, M. Impact of doping on the density of states and the mobility in organic semiconductors. Phys. Rev. B: Condens. Matter Mater. Phys. 2016, 93, 235203.

(16) Aubry, T. J.; Axtell, J. C.; Basile, V. M.; Winchell, K. J.; Lindemuth, J. R.; Porter, T. M.; Liu, J.-Y.; Alexandrova, A. N.; Kubiak, C. P.; Tolbert, S. H.; Spokoyny, A. M.; Schwartz, B. J. DodecaboraneBased Dopants Designed to Shield Anion Electrostatics Lead to Increased Carrier Mobility in a Doped Conjugated Polymer. Adv. Mater. 2019, 31, 1805647.

(17) Liang, Z.; Zhang, Y.; Souri, M.; Luo, X.; Boehm, A. M.; Li, R.; Zhang, Y.; Wang, T.; Kim, D.-Y.; Mei, J.; Marder, S. R.; Graham, K. R. Influence of Dopant Size and Electron Affinity on the Electrical Conductivity and Thermoelectric Properties of a Series of Conjugated Polymers. J. Mater. Chem. A 2018, 6, 16495.

(18) Hynynen, J.; Kiefer, D.; Yu, L.; Kroon, R.; Munir, R.; Amassian, A.; Kemerink, M.; Müller, C. Enhanced Electrical Conductivity of Molecularly p-Doped Poly(3-hexylthiophene) through Understanding the Correlation with Solid-State Order. Macromolecules 2017, 50, 8140.

(19) Qu, S.; Yao, Q.; Wang, L.; Chen, Z.; Xu, K.; Zeng, H.; Shi, W.; Zhang, T.; Uher, C.; Chen, L. Highly anisotropic P3HT films with 
enhanced thermoelectric performance via organic small molecule epitaxy. NPG Asia Mater. 2016, 8, No. e292.

(20) Hynynen, J.; Järsvall, E.; Kroon, R.; Zhang, Y.; Barlow, S.; Marder, S. R.; Kemerink, M.; Lund, A.; Müller, C. Enhanced Thermoelectric Power Factor of Tensile Drawn Poly(3-hexylthiophene). ACS Macro Lett. 2019, 8, 70.

(21) Hamidi-Sakr, A.; Biniek, L.; Bantignies, J.-L.; Maurin, D.; Herrmann, L.; Leclerc, N.; Lévêque, P.; Vijayakumar, V.; Zimmermann, N.; Brinkmann, M. A Versatile Method to Fabricate Highly In-Plane Aligned Conducting Polymer Films with Anisotropic Charge Transport and Thermoelectric Properties: The Key Role of Alkyl Side Chain Layers on the Doping Mechanism. Adv. Funct. Mater. 2017, 27, 1700173.

(22) Zhang, Q.; Sun, Y.; Xu, W.; Zhu, D. Thermoelectric energy from flexible P3HT films doped with a ferric salt of triflimide anions. Energy Environ. Sci. 2012, 5, 9639.

(23) Lim, E.; Peterson, K. A.; Su, G. M.; Chabinyc, M. L. Thermoelectric Properties of Poly(3-hexylthiophene) (P3HT) Doped with 2,3,5,6-Tetrafluoro-7,7,8,8-tetracyanoquinodimethane (F4TCNQ) by Vapor-Phase Infiltration. Chem. Mater. 2018, 30, 998.

(24) Untilova, V.; Biskup, T.; Biniek, L.; Vijayakumar, V.; Brinkmann, M. Control of Chain Alignment and Crystallization Helps Enhance Charge Conductivities and Thermoelectric Power Factors in Sequentially Doped P3HT:F-4 TCNQ Films. Macromolecules 2020, 53, 2441.

(25) Belasco, J.; Mohapatra, S. K.; Zhang, Y. D.; Barlow, S.; Marder, S. R; Kahn, A. Molecular doping and tuning threshold voltage in 6,13-bis(triisopropylsilylethynyl) pentacene/polymer blend transistors. Appl. Phys. Lett. 2014, 105, No. 063301.

(26) Paniagua, S. A.; Baltazar, J.; Sojoudi, H.; Mohapatra, S. K.; Zhang, S. Y.; Henderson, C. L.; Graham, S.; Barlow, S.; Marder, S. R. Production of heavily $\mathrm{n}$ - and $\mathrm{p}$-doped CVD graphene with solutionprocessed redox-active metal-organic species. Mater. Horiz. 2014, 1, 111.

(27) Mohapatra, S. K.; Zhang, Y. D.; Sandhu, B.; Fonari, M. S.; Timofeeva, T. V.; Marder, S. R.; Barlow, S. Synthesis, characterization, and crystal structures of molybdenum complexes of unsymmetrical electron-poor dithiolene ligands. Polyhedron 2016, 116, 88.

(28) Bruchlos, K.; Trefz, D.; Hamidi-Sakr, A.; Brinkmann, M.; Heinze, J.; Ruff, A.; Ludwigs, S. Poly(3-hexylthiophene) revisited Influence of film deposition on the electrochemical behaviour and energy levels. Electrochim. Acta 2018, 269, 299.

(29) Enengl, C.; Enengl, S.; Pluczyk, S.; Havlicek, M.; Lapkowski, M.; Neugebauer, H.; Ehrenfreund, E. Doping-Induced Absorption Bands in P3HT: Polarons and Bipolarons. ChemPhysChem 2016, 17, 3836.

(30) Simoes, M. C.; Hughes, K. J.; Ingham, D. B.; Ma, L.; Pourkashanian, M. Estimation of the Thermochemical Radii and Ionic Volumes of Complex Ions. Inorg. Chem. 2017, 56, 7566.

(31) Ghosh, R.; Chew, A. R.; Onorato, J.; Pakhnyuk, V.; Luscombe, C. K.; Salleo, A.; Spano, F. C. Spectral Signatures and Spatial Coherence of Bound and Unbound Polarons in P3HT Films: Theory Versus Experiment. J. Phys. Chem. C 2018, 122, 18048.

(32) Hofmann, A. I.; Kroon, R.; Zokaei, S.; Järsvall, E.; Malacrida, C.; Ludwigs, S.; Biskup, T.; Müller, C. Chemical Doping of Conjugated Polymers with the Strong Oxidant Magic Blue. Adv. Electron. Mater. 2020, 2000249.

(33) Bounioux, C.; Diaz-Chao, P.; Campoy-Quiles, M.; MartinGonzalez, M. S.; Goni, A. R.; Yerushalmi-Rozen, R.; Müller, C. Thermoelectric composites of poly(3-hexylthiophene) and carbon nanotubes with a large power factor. Energy Environ. Sci. 2013, 6, 918. (34) Lim, E.; Glaudell, A. M.; Miller, R.; Chabinyc, M. L. The Role of Ordering on the Thermoelectric Properties of Blends of Regioregular and Regiorandom Poly(3-hexylthiophene). Adv. Electron. Mater. 2019, 5, 1800915.

(35) Biniek, L.; Leclerc, N.; Heiser, T.; Bechara, R.; Brinkmann, M. Large Scale Alignment and Charge Transport Anisotropy of pBTTT Films Oriented by High Temperature Rubbing. Macromolecules 2013, 46, 4014.
(36) Biniek, L.; Pouget, S.; Djurado, D.; Gonthier, E.; Tremel, K.; Kayunkid, N.; Zaborova, E.; Crespo-Monteiro, N.; Boyron, O.; Leclerc, N.; Ludwigs, S.; Brinkmann, M. High-Temperature Rubbing: A Versatile Method to Align pi-Conjugated Polymers without Alignment Substrate. Macromolecules 2014, 47, 3871.

(37) Ghosh, R.; Luscombe, C. K.; Hambsch, M.; Mannsfeld, S. C. B.; Salleo, A.; Spano, F. C. Anisotropic Polaron Delocalization in Conjugated Homopolymers and Donor-Acceptor Copolymers. Chem. Mater. 2019, 31, 7033.

(38) Scheunemann, D.; Vijayakumar, V.; Zeng, H.; Durand, D.; Leclerc, N.; Brinkmann, M.; Kemerink, M. Rubbing and Drawing: Generic Ways to Improve the Thermoelectric Power Factor of Organic Semiconductors? Adv. Electron. Mater. 2020, 2000218. 